\title{
Successful Pregnancy Outcome with High dose Heparin Therapy in Antiphospholipid Antibody Syndrome
}

\author{
MP RANJ ITH, ${ }^{1}$ RANJ ITH DI VYA, ${ }^{2}$ S MEERA, ${ }^{3}$ SHABU BAHULEYAN, ${ }^{4}$ RONEY J OSEPH KURYAN ${ }^{5}$
}

\begin{abstract}
Antiphospholipid antibody syndrome is an autoimmune disease characterized by thrombosis, both arterial and venous, recurrent spontaneous abortion and the persistence of positive antiphospholipid antibodies. Placental thrombosis is believed to be the cause of recurrent abortions, characteristic of the syndrome. We report a pregnant with antiphospholipid antibody syndrome patient with history of recurrent miscarriages and managed successfully with high dose heparin.
\end{abstract}

Keyword: Antiphospholipid antibody syndrome, recurrent intra uterine death, Heparin

\section{Introduction}

Antiphospholipid antibodies (aPL) are recognized as the most frequent acquired risk factor for recurrent thrombosis and as a treatable cause of recurrent pregnancy loss. ${ }^{1}$ The pathogenic role of antiphospholipid antibodies was clearly shown in experimental animals that, when infused during pregnancy, develop placental insufficiency and miscarriages. Treatment of pregnant, aPL positive women to improve pregnancy outcome is completely empirical. ${ }^{2}$ Since 1992 heparin, combined with low dose aspirin, has replaced prednisone for treatment of pregnant aPL positive women in many centers. Medical treatment should be individualized, the kind of prophylactic treatment outside pregnancy and the obstetric history will determine whether aspirin or low molecular weight heparin, or both, or anticoagulation at high intensity seems most appropriate.

\section{Case report}

A 26 year old lady presented in our outpatient department with 4 month history of amenorrhea and positive urine pregnancy test. She gives history of previous three unexplained intra uterine death (IUD) at 27, 24, 26 weeks of gestation, with morphologically normal foetus. There was no history any arterial or venous thrombosis in the past. During her last pregnancy, 2 years back she was diagnosed to have aPL antibodies and was treated with heparin from a local hospital but she missed the baby at 26 weeks.

General examination and vitals were unremarkable. Obstetric sonogram showed a single intra uterine live foetus of gestational age 14 weeks 6 days. Laboratory investigation showed a blood sugar of $98 \mathrm{mg} \%$ and a normal complete hemogram, liver function test renal function test and coagulation profile. Anticardiolipin IgM and IgG antibody, Anti nuclear antibody (ANA) were positive. Anti Ds DNA antibody was negative. The diagnosis of antiphodpholipid antibody syndrome (APS) was confirmed as per standard criteria. ${ }^{3}$ She was immediately put on Aspirin 150mg OD and unfractionated Heparin5000 unit BD. After one week her ApTT was 65 (normal 25 to 35 seconds).She was regularly followed-up with doppler study.

Doppler study of umbilical artery at 22 weeks showed decreased diastolic flow so dose of heparin increased to 5000 QID. At 26 weeks diastolic flow again decreased and heparin dose increased to 7500 QID. At 31 weeks doppler showed absent diastolic flow (Figure 1) and aPTT and PT were normal. The dose heparin was titrated to 10000 unit QID and repeat doppler study at next day showed patent diastolic flow with Systolic Diastolic ratio 3.17 (Figure 2). During this period patient didn't had any bleeding episodes. She was also given 1000mg calcium daily. At 34 weeks pregnancy was terminated by caesarean section because of fetal bradycardia. Baby was of $1.4 \mathrm{~kg}$ and neonatal period was uneventful.

The mother was put on warfarin prophylaxis and at followup after 6 month she didn't have any thrombotic episodes and baby was developed up to age.

1. Consultant Physician, Department of Medicine, Melepurakkal Hospital, Malappuram, India

2. Consultant Physician, Department of Medicine, Melepurakkal Hospital, Malappuram, India

3. Obstretitian \& Gynaecologist, Department of O\&G, Melepurakkal Hospital,Malappuram, India

4. Consultant Paediatrician, Department of Paediatrics, Melepurakkal Hospital,Malappuram, India

5. Anaesthesiologist, Melepurakkal Hospital, Malappuram, India

Correspondence: MP Ranjith, Consultant Physician, Department of Medicine, Melepurakkal Hospital, Malappuram, India. E-mail: drranjithmp@gmail.com 


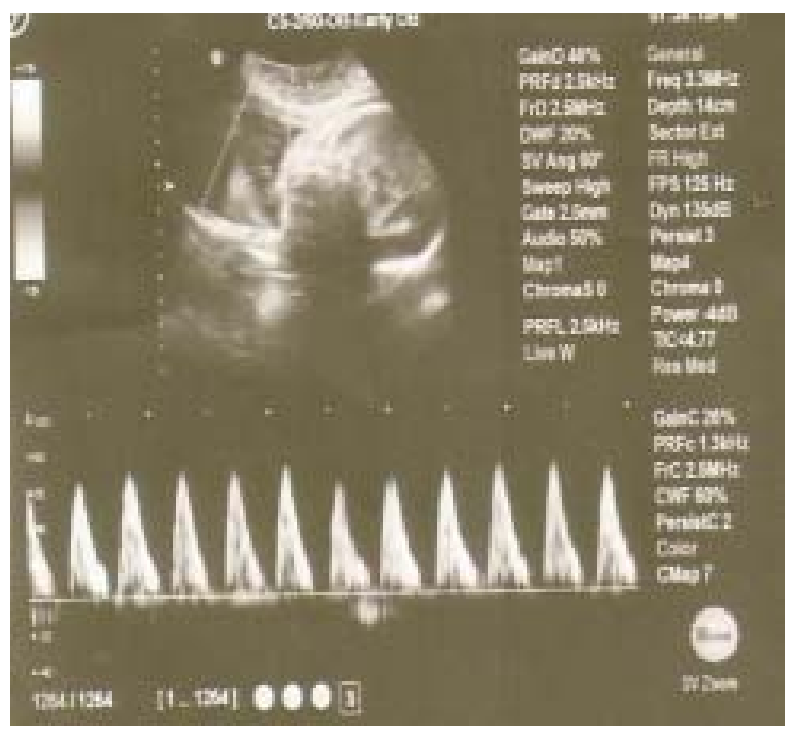

Fig.-1: Umbilical artery doppler at 31 weeks showing absent diastolic flow.

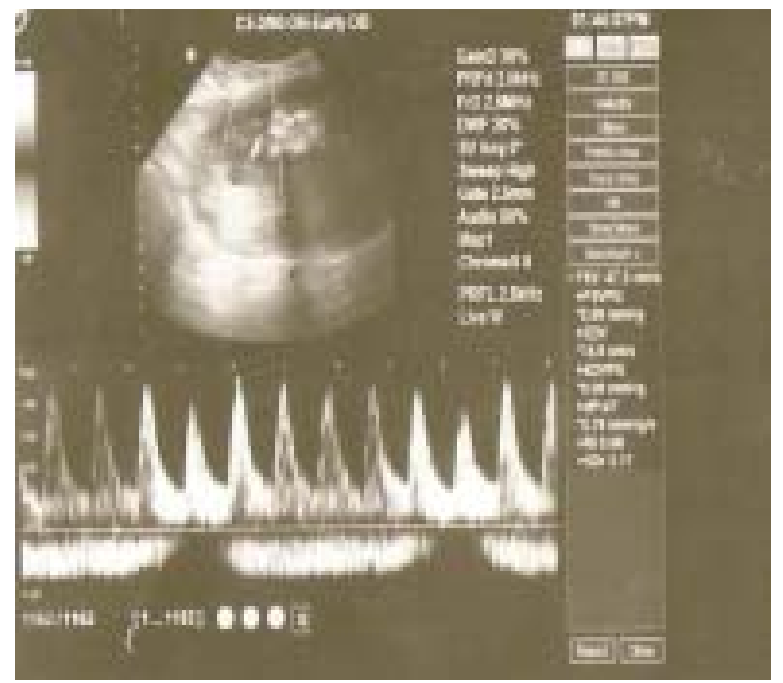

Fig.-2: Umbilical artery doppler study at 31 weeks after giving 40000 units heparin showing patent diastolic flow with Systolic Diastolic ratio 3.17.

\section{Discussion}

The term "antiphospholipid syndrome” was first coined to denote the clinical association between antiphospholipid antibodies and a syndrome of hypercoagulability. ${ }^{4,5}$ Our patient had three unexplained IUD with aPL antibody and ANA positivity. The available literatures mention that aspirin and heparin are the treatment of choice but there are no clear cut guidelines for the dose of heparin. ${ }^{2}$ In our patient we have started with 5000 unit heparin in twice daily dose but we had to increase the dose up to 10000 unit six hourly in order to maintain target aPTT and intrauterine diastolic flow. The patient didn't have any bleeding episodes.

Available literature mentions about the use of heparin up to 20000 units per day in the management of APS but in this patient we have used heparin up to 40000 units daily. ${ }^{6}$ We also gave high dose calcium (1000 mg) daily to prevent osteoporosis and she was followed up with regular checking of coagulation profile.

Spiros Dendrinos et al reported that low molecular weight heparin plus low-dose aspirin resulted in a higher live birth rate than intravenous immunoglobulin in the treatment of antiphospholipid antibody syndrome in women with recurrent abortion. ${ }^{7}$ A recent intervention review by Marianne B Empson et al concludes that a combination of unfractionated heparin with aspirin may be helpful but there are potential side-effects for mothers. ${ }^{6}$

Based on our report the dose of heparin needed for a successful outcome in pregnant ladies with APS should be individualized and should be titrated depending up on the clinical and investigation findings. Hence heparin can be used up to 40000 units per day in managing patients with APS without any bleeding episode provided strict monitoring of coagulation profile is done.

\section{Conflict of interest: None}

\section{References}

1. Levine JS, Branch DW, Rauch J. The antiphospholipid syndrome. N Engl J Med 2002; 346: 752-63

2. R H W M Derksen, Ph G de Groot, H K Nieuwenhuis, et al. How to treat women with antiphospholipid antibodies in pregnancy? Ann Rheum Dis 2001;60: 1-3

3. Brandt JT, Triplett DA, Alving B, Scharrer I. Criteria for the diagnosis of lupus anticoagulants: an update. Thromb Haemost 1995;74:1185-90.

4. Hughes GRV, Harris EN, Gharavi AE. The anticardiolipin syndrome. J Rheumatol 1986; 13: 486-9.

5. Alarcón-Segovia D, Delezé M, Oria CV, et al. Antiphospholipid antibodies and the antiphospholipid syndrome in systemic lupus erythematosus: a prospective analysis of 500 consecutive patients. Medicine (Baltimore) 1989;68:353-65.

6. . Empson MB, Lassere M, Craig JC, Scott JR. Prevention of recurrent miscarriage for women with antiphospholipid antibody or lupus anticoagulant. Cochrane Database of Systematic Reviews 2005, Issue 2. Art. No.: CD002859.

7. Spiros Dendrinos, Evangelos Sakkas, Evangelos Makrakis. Low-molecular-weight heparin versus intravenous immunoglobulin for recurrent abortion associated with antiphospholipid antibody syndrome. Int J Gynecol Obstet 2009;104(3):223-225. 